\title{
Hyperlipidemia in association with pro-inflammatory cytokines among chronic spontaneous urticaria: case-control study
}

${ }^{1}$ Department of Internal Medicine, Allergy and Clinical immunology, Faculty of Medicine, Ain Shams University, Cairo, Egypt ${ }^{2}$ Department of Clinical and Chemical Pathology, Faculty of Medicine, Ain Shams University, Cairo, Egypt

\section{KEY WORDS}

chronic spontaneous urticaria; hyperlipidemia; IL6; lipid profile; TNFa

\section{Corresponding author \\ Mariam Maged Amin \\ Khalifa El-Maamon st \\ Abbasiya square, 11566 Cairo, Egypt \\ Phone: +20 201224532769 \\ E-mail: mariamaged@yahoo.com}

\section{Doi}

10.23822/EurAnnACI.1764-1489.68

\begin{abstract}
Summary
Chronic spontaneous urticaria (CSU) is a disorder characterized by recurrent transient itchy wheels of 6 weeks duration or longer. The cause cannot be pinpointed in about $40 \%$ of patients. To elucidate the possible association between CSU and hyperlipidemia, 40 CSU patients and 40 group matched healthy individuals were assessed for hyperlipidemia. Data on history, urticaria activity score (UAS-7), physical examination and routine laboratory investigations including lipid profile (serum ILG and TNF $\alpha$ ) was recorded. Statistically significant in-crease of serum cholesterol, triglycerides (TG), low density lipoprotein (LDL), ILG, TNFa and decrease of high density lipoprotein (HDL) was found in CSU in comparison to control group. Regarding the different disease variables, both TG and cholesterol were positively correlated with duration of illness, urticaria activity score and serum TNF $\alpha$. Serum LDL detected significant positive correlation with duration of illness, urticaria score, CRP and TNF $\alpha$ while serum HDL detected significant negative correlation with TNF $\alpha$. IL6 and TNF $\alpha$ associated systemic inflammation could be a common pathogenic mechanism of CSU and hyperlipidemia. Patients with CSU should be evaluated for hyperlipidemia.
\end{abstract}

\section{Introduction}

Urticaria is described as wheals (swelling/erythema) and/or angioedema lasting for 1-24 hours. The European Academy of Allergy and Clinical immunology (EAACI), the Global Allergy and Asthma European Network (GA2LEN), the European Dermatology Forum (EDF) and the World Allergy Organization (WAO) guidelines sorted urticaria according to the duration and cause. Urticaria lasting more than 6 weeks is divided into two categories; inducible or spontaneous urticaria $(1,2)$.

Chronic spontaneous urticaria (CSU) is stated as an immuno-inflammatory disorder characterized by the recurrent occurrence of wheals and/or angioedema lasting for more than 6 weeks (1). Causes of CSU may be known (e.g. autoantibodies) or unknown. Autoimmune mechanisms have been considered in $30-50 \%$ of cases (3). The inducible urticaria has variable triggers (cold, delayed pressure, solar, heat, vibratory, cholinergic, contact, and aquagenic) urticaria. More than one type of urticaria can coexist in the same patient (4). The natural course of CSU is self-limiting, with spontaneous remissions and exacerbations, however, impairment of the quality of life is usually severe (5). Though the pathogenesis of CSU remains unknown, some studies have revealed the existence of intrinsic abnormalities in basophils or mast cells $(6,7)$. Nonetheless, CSU inflammatory processes are not restricted to the consequences of mast/basophil degranulation (7). CSU is characterized by cutaneous mast cell degranulation, in addition to infiltration of the skin by eosinophils, neutrophils and T lymphocytes (8). 
Foregoing studies suggested that immunological malfunction is the primary background in CSU. This is confirmed by the dysfunctional innate immune response which was found in CSU patients in the form of increased levels of C-reactive protein (CRP), proinflammatory cytokines such as interleukin (IL-6), tumor necrosis alpha (TNF- $\alpha$ ), and matrix metalloproteinase-9 with an altered pattern of regulatory cytokine secretion (9). These inflammatory markers were noticed to harmonize well with activity score of urticaria and its severity $(7,9,10)$.

Also, a systemic pro-inflammatory state marked by the elevation of serum level of inflammatory mediators as IL-6, TNF, and CRP are detected in patients with metabolic syndrome (obesity, dyslipidemia, elevated blood pressure, and plasma glucose level). Dyslipidemia was incriminated to be involved in the inflammatory mechanisms of atherosclerosis associated with metabolic syndrome (11).

Consequently, both CSU and metabolic syndrome have been characterized by systemic inflammation which was pinpointed in various studies $(12,13)$. Furthermore, a greater frequency of metabolic syndrome was detected in patients with CSU compared to healthy controls (13). However, few studies have yet specifically determined a link between hyperlipidemia and CSU. Thus, the aim of the current study was to clarify the possible association between hyperlipidemia and proinflammatory cytokines among chronic urticaria patients.

\section{Methodology}

\section{Study participants}

Forty patients with established diagnosis of chronic spontaneous urticaria according to standard European Academy of Allergology and Clinical Immunology/the Global Allergy and Asthma European Network (EAACI/GA2LEN) guidelines (2) were enrolled in the study. They were recruited from the allergy clinic of Ain Shams University hospital during the period from February 2015 to March 2017. The diagnosis of CSU was considered if the wheals last for 6 weeks or longer at least 2 times a week and its underlying cause remained unidentified notwithstanding the appropriate investigations with pseudoallergen-free diet for 3 weeks. No one of the participants was smoker, body mass index more than 25, had food/medication induced allergy including NSAIDS hypersensitivity or autoimmune diseases including thyroid autoimmune diseases, or urticarial vasculitis. Other exclusion criteria were inducible urticarial lesions by chronic infections, $\mathrm{H}$ pylori, environmental agents, stress or physical agents as cholinergic stimulation, dermatographism or pressure. Another forty group-matched healthy individuals were enrolled as a control group. The study was approved by the allergy and clinical immunology review board and research ethics committee of Ain Shams University. All participants did sign an informed consent.

\section{Study design}

All participants were subjected to detailed history including past and family history as well as urticaria activity score (UAS7) and complete clinical examination excluding the aforesaid etiologies. The onset, duration, characteristics and distribution of lesions, history of any associated medical illness or allergies, drug history were recorded. Standard investigations were executed as skin test for allergy including physical tests, autologous serum skin test, urine analysis, stool analysis, Helicobacter pylori antigen, liver enzymes, kidney function tests, complete blood picture, thyroid antibodies, ESR, CRP, hepatitis $\mathrm{C}$ virus antibody, hepatitis B virus surface antigen and human immunodeficiency virus antibodies.

\section{Assessment of urticaria activity score}

We assessed CSU disease activity using the weekly urticaria activity score (UAS-7). It is evaluated according to the number of wheals and pruritus intensity assumed on the EAACI/GA2LEN/EDF guidelines. We asked the patients to record scores of 24 hours self-evaluation for 7 days and documented it as: no wheals $=0 ;<20$ wheals $/ 24$ hour $=1 ; 20-50$ wheals $/ 24$ hour $=$ 2 ; and $>50$ wheals $/ 24$ hour $=3$; and pruritus intensity: no $=$ 0 ; mild $=1$; moderate $=2$; and severe $=3$. The weekly UAS-7 (equal to the sum of the scores on 7 consecutive days) ranges from $(0-42)(2)$.

\section{Skin Prick Test}

We performed the skin prick test using the most conventional aeroallergen extracts. The result was interpreted after 15-20 minutes. It was considered justifiable when the difference in mean wheal diameters was at least $1 \mathrm{~mm}$ between the histamine (positive) and saline (negative) controls. Patient is considered sensitized to that peculiar allergen when a wheal diameter is $\geq 3$ $\mathrm{mm}$ more than the negative control (14).

\section{Autologous serum skin test}

Participants stopped all medications containing antihistamines and corticosteroids for at least 5 days before performance of the test. We performed the test according to the EAACI/GA2LEN task force consensus guidelines. The test is positive when a serum-induced wheal is at least $1.5 \mathrm{~mm}$ more than that induced by saline after 30 minutes (15). 
Anti-nuclear antibody, anti-thyroid antibodies and inflammatory markers

Anti-nuclear antibody, anti-thyroglobulin, and thyroid microsomal antibodies were measured using indirect fluorescent antibody technique using (INOVA Diagnostics, San Diego, CA). Serum levels of C-reactive protein were assayed by immunoturbidimetry using kit supplied by Behring Diagnostics $(\mathrm{GmbH}$, Marburg, Germany). Commercially available enzyme-linked immunosorbent Assay (ELISA) kits were utilized for assessment of TNF- $\alpha$ (Sigma-Saint Louis, Missouri, Germany) (Catalog number: CKH-200A) with kit sensitivity $4.4 \mathrm{pg} / \mathrm{ml}$, and IL-6 ELISA kits (Biocompare; antibodies-online; Schloss-Rahe-Str. 15, Aachen, Germany) (Catalog number: ABIN414297) with assay sensitivity $6.4 \mathrm{pg} / \mathrm{mL}$.

\section{Lipid profile}

Lipid profile was done including fasting cholesterol, low-density lipoprotein (LDL), high-density lipoprotein (HDL), and triglycerides measured on Synchron CX9 auto-analyzer (Beckman Instruments Inc.; Scientific Instruments Division, Fullerton, CA 92634-3100, USA).

\section{Statistical Analysis}

Data were analyzed using SPSS version 22 (IBM). Shapiro-Wilk test was used to examine normality of numerical data distribu- tion. Mean and SD represented the normally distributed numerical variables and the two independent sample (unpaired) Student t-test was used to compare intergroup differences between the two groups. Levene's test was used to examine equality of variances between groups. Mean and SD represented the non-normally distributed numerical data and Mann-Whitney $U$ test was used to compare intergroup differences between the two groups. Pearson's correlation was used to check normally distributed variables for linear correlation. However, Spearman's Rank correlation was used for Non-Normally distributed variables. Categorical variables were presented as number or proportion and percentage, and intergroup differences were compared using Fischer's exact test (for nominal data) or Chi-Squared Test for Trend (for ordinal data). The diagnostic value of serum continuous variables was examined by Receiver-operating characteristic (ROC) curve analysis. The area under the ROC Curve (AUC) was compared with that of random prediction. The relationship between normally distributed variables was investigated by linear regression and curve estimation was used to plot these relations. A two-sided $\mathrm{p}$-value $<0.05$ was considered statistically significant. A two-sided p-value $<0.01$ was considered highly statistically significant.

\section{Results}

Clinical and laboratory characteristics of both cases and control groups are shown in table I. Cases included 22 males and 18 females. Their mean age was $37.13 \pm 10.371$. Mean age of controls was $37.03 \pm 10.58$ years. 19 were males and 21 were

Table I - Demographic data and laboratory investigations of both studied groups.

\begin{tabular}{|c|c|c|c|c|c|c|c|}
\hline & & \multicolumn{4}{|c|}{ Group } & \multirow{2}{*}{\multicolumn{2}{|c|}{ test of significance }} \\
\hline & & \multicolumn{2}{|c|}{ cases } & \multicolumn{2}{|c|}{ control } & & \\
\hline & & mean/n & $\mathrm{SD} / \%$ & mean/n & $\mathrm{SD} / \%$ & p-Value & sig. \\
\hline age (years & & 37.13 & 10.37 & 37.03 & 10.58 & $0.966^{\mathrm{T}}$ & ns \\
\hline \multirow{2}{*}{ gender } & male & 22 & $55 \%$ & 19 & $47.50 \%$ & \multirow{2}{*}{$0.655^{\mathrm{F}}$} & \multirow{2}{*}{ ns } \\
\hline & female & 18 & $45 \%$ & 21 & $52.50 \%$ & & \\
\hline \multicolumn{2}{|c|}{ duration of illness (month) } & 8.25 & 4.37 & & & & \\
\hline \multicolumn{2}{|c|}{ urticarial severity score } & 18.9 & 12.3 & & & & \\
\hline \multicolumn{2}{|c|}{ serum IL6 $(\mathrm{pg} / \mathrm{ml})$} & 8.73 & 17.79 & 28.87 & 31.64 & $<0.001^{\mathrm{M}}$ & $\mathrm{s}$ \\
\hline \multicolumn{2}{|c|}{ serum TNF $\alpha(\mathrm{pg} / \mathrm{ml})$} & 11.25 & 16.6 & 38.71 & 34.89 & $<0.001^{\mathrm{M}}$ & $s$ \\
\hline \multicolumn{2}{|c|}{ serum CRP $(\mathrm{mg} / \mathrm{dl})$} & 11.58 & 5.65 & 19.89 & 18.37 & $0.266^{\mathrm{M}}$ & ns \\
\hline \multicolumn{2}{|c|}{ serum TG $(\mathrm{mg} / \mathrm{dl})$} & 143.8 & 23.36 & 179.23 & 31.26 & $<0.001^{\mathrm{T}}$ & $\mathrm{s}$ \\
\hline \multicolumn{2}{|c|}{ serum cholesterol $(\mathrm{mg} / \mathrm{dl})$} & 150.68 & 49.41 & 248.45 & 58.43 & $<0.001^{\mathrm{M}}$ & $s$ \\
\hline \multicolumn{2}{|c|}{ LDL (mg/dl) } & 175.2 & 61.9 & 77.9 & 50.3 & $<0.001^{\mathrm{M}}$ & s \\
\hline \multicolumn{2}{|c|}{$\operatorname{HDL}(\mathrm{mg} / \mathrm{dl})$} & 40.43 & 6.87 & 44.38 & 5.02 & $0.004^{\mathrm{T}}$ & $\mathrm{s}$ \\
\hline
\end{tabular}

${ }^{\mathrm{M}}$ Mann-Whitney test; ${ }^{\mathrm{T}}$ t-test; ${ }^{\mathrm{F}}$ Fisher's Exact test. 
females. Serum level of IL, TNF $\alpha$, Cholesterol, TG, LDL and HDL were highly elevated with statistical significance in group of patients compared to control group with p-value $(<0.001,<$ $0.001,<0.001,<0.001,<0.001,0.004)$ respectively. However, non-significant difference regarding gender, age or CRP was found.

Table II exhibits the correlation of serum IL6 and TNF $\alpha$ level with different disease variables, in which serum IL6 show significant positive correlation with urticaria activity score $(\mathrm{p}=0.031)$. Serum TNF $\alpha$ was positively correlated with duration of illness (p-value $<0.001)$ and urticaria activity score (p-value $<0.001$ ) with statistical significance. However, no statistically significant difference of both in relation to age or gender.

The descriptive and statistical difference of serum TG and cholesterol levels as regard the different disease variables is shown in table III, in which both TG and cholesterol were positively correlated with duration of illness ( $p<0.001,<0.001)$, urticaria activity score $(\mathrm{p}=0.003,<0.001)$ and serum TNF $\alpha(\mathrm{p}=0.024$, $<0.001)$, respectively.

Regarding the different disease variables, serum LDL detected significant positive correlation with duration of illness $(\mathrm{p}=<0.001)$, urticaria activity score $(\mathrm{p}=<0.001)$, serum CRP $(\mathrm{p}=<0.001)$ and TNF $\alpha(\mathrm{p}=<0.001)$ while serum HDL was negatively correlated with serum TNF $\alpha(\mathrm{p}=0.033)$ as shown with statistical significance in table IV.

Diagnostic performance of (cholesterol/TG) as a cause of CSU is shown in figure 1. At the cut-off value of Cholesterol $163 \mathrm{mg} /$ $\mathrm{dl}$; the sensitivity $=92 \%$, specificity $=85 \%, \mathrm{PPV}=86.0 \%$ and $\mathrm{NPV}=91.9 \%$. While at the cut-off value of TG $154 \mathrm{mg} / \mathrm{dl}$; the sensitivity $=80 \%$, specificity $=67.5 \%, \mathrm{PPV}=68.1 \%$ and NPV $=$ $75.8 \%$. At the cut-off value of $\mathrm{LDL}>88 \mathrm{mg} / \mathrm{dl}$; the sensitivity $=$ $92.500 \%$, specificity $=80 \%, \mathrm{PPV}=82.2 \%$ and NPV $=91.4 \%$. While at the cut-off value of $\mathrm{HDL}<40 \mathrm{mg} / \mathrm{dl}$; the sensitivity $=57.5 \%$, specificity $=80 \%, \mathrm{PPV}=74.2 \%$ and $\mathrm{NPV}=65.3 \%$.

Table II - Correlation between serum levels of both ILG, TNFa with different disease variables.

\begin{tabular}{ccccc}
\hline \multicolumn{2}{c}{ Correlation between cases group } & age & urticaria severity score & duration of illness \\
\hline \multirow{2}{*}{ serum IL6 $(\mathrm{pg} / \mathrm{ml})$} & Pearson Correlation & $-0.129^{\mathrm{P}}$ & $0.342^{\mathrm{P}}$ & $0.15^{\mathrm{S}}$ \\
\cline { 2 - 5 } & $\mathrm{p}$-Value & 0.254 & 0.031 & 0.354 \\
\cline { 2 - 5 } & sig. & $\mathrm{NS}$ & $\mathrm{S}$ & $\mathrm{NS}$ \\
\hline \multirow{2}{*}{ serum TNF $\alpha(\mathrm{pg} / \mathrm{ml})$} & Pearson Correlation & $0.105^{\mathrm{S}}$ & $0.869^{\mathrm{S}}$ & $-0.819^{\mathrm{S}}$ \\
\cline { 2 - 5 } & sig. (2-tailed) & 0.355 & $<0.001$ & $<0.001$ \\
\cline { 2 - 5 } & sig. & $\mathrm{NS}$ & $\mathrm{S}$ & $\mathrm{S}$ \\
\hline
\end{tabular}

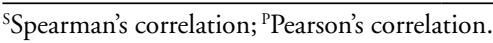

Table III - Correlation between serum levels of both cholesterol and TG with different disease variables.

\begin{tabular}{|c|c|c|c|c|c|c|c|}
\hline \multicolumn{2}{|c|}{ Correlation between cases group } & \multirow{2}{*}{$\begin{array}{c}\text { age } \\
-0.072^{\mathrm{P}}\end{array}$} & \multirow{2}{*}{$\begin{array}{c}\begin{array}{c}\text { urticaria } \\
\text { score }\end{array} \\
0.819^{\mathrm{S}}\end{array}$} & \multirow{2}{*}{$\begin{array}{c}\begin{array}{c}\text { duration of } \\
\text { illness }\end{array} \\
0.869^{S}\end{array}$} & \multirow{2}{*}{$\begin{array}{c}\text { IL6 } \\
0.291\end{array}$} & \multirow{2}{*}{$\begin{array}{c}\text { TNFa } \\
0.637\end{array}$} & \multirow{2}{*}{$\begin{array}{c}\text { CRP } \\
0.0585\end{array}$} \\
\hline serum cholesterol (mg/dl) & $\begin{array}{l}\text { Pearson } \\
\text { correlation }\end{array}$ & & & & & & \\
\hline & p-Value & 0.528 & $<0.001$ & $<0.001$ & 0.069 & $<0.001$ & $<0.001$ \\
\hline & sig. & $\mathrm{ns}$ & $\mathrm{s}$ & $s$ & $\mathrm{~ns}$ & $s$ & $s$ \\
\hline \multirow[t]{3}{*}{ serum TG $(\mathrm{mg} / \mathrm{dl})$} & $\begin{array}{l}\text { Pearson } \\
\text { correlation }\end{array}$ & $-0.08^{S}$ & $0.46^{S}$ & $0.504^{\mathrm{S}}$ & 0.292 & 0.356 & 0.217 \\
\hline & sig. (2-tailed) & 0.478 & 0.003 & $<0.001$ & 0.068 & 0.024 & 0.179 \\
\hline & sig. & ns & $\mathrm{s}$ & $s$ & ns & $s$ & ns \\
\hline
\end{tabular}

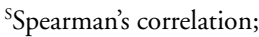

PPearson's correlation. 
Table IV -Correlation between serum level of both $L D L$ and $H D L$ with different disease variables.

\begin{tabular}{ccccccccc}
\hline \multicolumn{2}{c}{ Correlation between cases group } & age & urticaria score & duration of illness & IL6 & TNF $\boldsymbol{\alpha}$ & CRP \\
\hline \multirow{2}{*}{ DLL (mg/d) } & Pearson correlation & -0.198 & 0.843 & 0.708 & 0.272 & 0.739 & 0.566 \\
\cline { 2 - 9 } & $\mathrm{p}$-Value & 0.222 & $<0.001$ & $<0.001$ & 0.089 & $<0.001$ & $<0.001$ \\
\cline { 2 - 9 } & sig. & $\mathrm{ns}$ & $\mathrm{s}$ & $\mathrm{s}$ & $\mathrm{ns}$ & $\mathrm{s}$ & $\mathrm{s}$ \\
\hline \multirow{2}{*}{$\mathrm{HDL}(\mathrm{mg} / \mathrm{d})$} & Pearson correlation & 0.119 & -0.182 & -0.149 & -0.086 & -0.341 & -0.169 \\
\cline { 2 - 9 } & sig. (2-tailed) & 0.464 & 0.260 & 0.360 & 0.599 & 0.033 & 0.296 \\
\cline { 2 - 9 } & sig. & $\mathrm{ns}$ & $\mathrm{ns}$ & $\mathrm{ns}$ & $\mathrm{ns}$ & $\mathrm{s}$ & $\mathrm{ns}$ \\
\hline
\end{tabular}

Figure 1-ROC for significance of lipid profile as cause of urticaria.

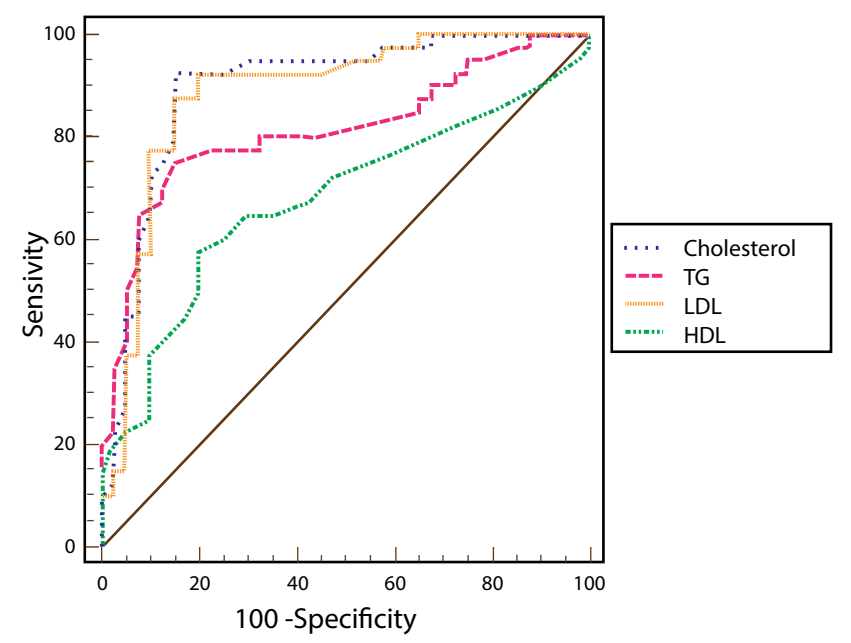

\section{Discussion}

The pathogenesis of chronic spontaneous urticaria (CSU) remains unknown, but autoimmune abnormalities, disorders of histamine-releasing factors, and cellular defects have all been involved (16). Patients with CSU have an increased risk of antecedent hyperlipidemia. Little studies had formerly reported a link between hyperlipidemia and CSU, however, an increased level of inflammatory markers as IL-1, Il-6, and TNF- $\alpha$ in both patients with CSU and those with metabolic syndrome has been signified $(9,10,11)$. Hence, the rationale of the current study was to investigate the possible association between chronic urticaria and hyperlipidemia.

In our study, there was highly statistically significant increase in group 1 compared to group 2 in serum Cholesterol, TG, LDL, and statistically significant decrease in HDL. However, non-significant difference regarding gender, age or CRP was found. TG and cholesterol were positively correlated with duration of illness, urticaria activity score and serum TNF $\alpha$. Serum LDL was positively correlated with duration of illness, urticaria activity score, serum CRP, TNF $\alpha$, and serum HDL detected significant negative correlation with serum TNF $\alpha$.
This is in correspondence with Chung and colleagues, who found a 1.65 -fold increased risk of antecedent hyperlipidemia in 36.1\% of CU patients in comparison to controls after adjusting for possible confounding factors (17). Another cross-sectional study was conducted on 131 patients in Korea and concluded that metabolic syndrome was an independent predictor of uncontrolled CSU (13). This is in agreement with our study, but ours detected only the hyperlipidemia among patients with CSU.

In addition, Kobayashi detected in patients with in comparison to with controls elevation of serum lipids, cholesterol, B-lipoprotein and phospholipids (18). Also, Kobayashi and coworkers investigated serum lipids further (19) and found a correlation between serum lipids, fatty acids and chronic urticaria (20). These laboratory results suggested that serum lipids and fatty acids are chemical mediators and play a role in inducing urticaria.

These outcomes can be clarified by several probabilities. Various studies found an association between hyperlipidemia and inflammatory markers which were also observed in CSU $(9,10,21)$. Besides, CSU is considered a skin disease, induced by mast cells activation (22), which were also linked with hyperlipidemia or atherosclerotic disease. Mast cells, as a part of both innate and adaptive immune system, could have a role in endothelial inflammation (23) which was found to be corresponding to the atherosclerotic disease immensity (24).

Vascular mast cells, present within the adventitia and atherosclerotic plaques, (25) can modify lipid metabolism by hindering the ApoE- and ApoA-II-dependent cholesterol efflux (26). Besides, increased collagen content was observed in mast cell-deficient mice in addition to fibrous cap development, and reduced local inflammation leading to decreased atherosclerosis (27).

Mast cells which accumulate in the atherosclerotic lesions (28) are then activated by the pro-inflammatory stimuli, as C3a and C5a, and oxidized low-density lipoprotein (LDL) (29). Activated mast cells, in turn, release a broad array of proinflammatory cytokines affecting the development of CSU (22). Thus, the potential link between hyperlipidemia and CSU may be due to the presence of systemic inflammation which influences them both. Whether systemic inflammation or mast cells activation are involved in the pathogenesis of CSU following hyperlipidemia need further research to clarify. 
The current study detected a highly statistically significant increase in group 1 in contrast to group 2 as regards serum IL6 and TNFa. Serum IL6 show significant positive correlation with urticaria activity score while serum TNF $\alpha$ shows significant positive correlation with duration of illness (p-0.003) and urticaria activity score.

This is in agreement with Kasperska-Zajac and coworkers, who observed significant elevation of serum IL- 6 and CRP in CSU patients compared with the healthy controls. IL- 6 concentration was positively correlated with weekly UAS-7 and the different degrees of urticarial activity. Increased serum IL-6 in association with CRP changes reflect the link between CSU and systemic inflammation (10).

Our results are also in accordance with Young-Min and colleagues who found patients with metabolic syndrome to be older, and had a higher mean UAS and serum levels of TNF- $\alpha$ compared with controls (13). However, our study studied only patients with hyperlipidemia who had higher level of TNF $\alpha$ and positively correlated with urticaria activity score but had non-significant correlation with age.

Mast cells and basophils are the predominant cells in the development of chronic urticaria (30), in which proinflammatory cytokines as TNF- $\alpha$ and IL- 6 are incremented in the initiation and progression of their degranulation process $(31,32)$. Levels of TNF- $\alpha$ was found to be significantly elevated in patients with CU with metabolic syndrome, and were directly harmonized with higher UAS. This is in agreement with foregoing studies, which showed that plasma levels of TNF- $\alpha$, IL- 6 and CRP were significantly correlated with CSU clinical activity (10). Consequently, TNF- $\alpha$ inhibitors may beneficial in refractory CSU (33) as elevated serum levels of IL- 6 and TNF- $\alpha$ induce basophil activation, histamine release and leukotriene production in CSU (34).

Moreover, a link between hypertriglyceridemia and increased TNF- $\alpha$ serum level is detected (36). TNF- $\alpha$ can affect serum level of TG by acting on both adipose tissue and liver. It increases the production of free fatty acids (37), decrease level of TGrich lipoproteins (VLDLs) in the circulation by diminishing its clearance (36) and stimulates lipolysis in human adipose tissue (38). TNF- $\alpha$ can also increase plasma TG concentrations by the inhibition of lipoprotein lipase activity (39).

Besides, TNF- $\alpha$ may interfere with cholesterol metabolic pathways. TNF- $\alpha$ can inhibit the expression and activity of the ratelimiting enzyme of cholesterol elimination leading to decrease hepatic cholesterol catabolism and excretion (40). Moreover, it can down-regulate the activities of rate-limiting enzymes in the alternative pathway of bile acid synthesis. Hence, TNF- $\alpha$ decreases cholesterol elimination from the body and its availability during the acute phase response for other hepatic processes (41). IL-6 concentration is increased in CSU (42) and coordinated with its activity (10). IL-6, in addition, can lead to lipid abnormalities (43) through inhibition of adipocyte lipoprotein lipase activity (44), increased induction of hepatic triglyceride secretion (45) and increased plasma free fatty acids (FFAs) (46). Hence cytokines operate both as a cascade and as a network regulating the production of each other, increased IL- 6 may reflect the actions of other cytokines as TNF- $\alpha$.

Different immunomodulatory therapies were assessed in CSU including statins (47). Statins, apart from their lipid-lowering activity, have anti-inflammatory effects on basophils and the major proinflammatory effector cells by multiple mechanisms (48). Statins can inhibit the growth and activation of human basophils, as detected by Majlesi and colleagues (49). Administration of statins for 3 months, decreased the patients' symptoms assessed by urticarial score compared to before treatment. Hence, statins could be effective not only in hyperlipidemia but also in the treatment of chronic urticaria and it could alleviate the patients' symptoms in severe and resistant forms of urticaria (47).

\section{Conclusion}

There is a link between CSU and hyperlipidemia. IL6 and TNF- $\alpha$ associated systemic inflammation could be a common pathogenic mechanism of CSU and hyperlipidemia. More studies are needed on wider scales to clarify the possible pathophysiological mechanisms for prevention and early identification. Patients with severe and uncontrolled CSU should be evaluated for hyperlipidemia to improve CSU outcomes. We can reduce atherosclerosis and its complications with prompt detection and suitable management. Thus, both of CSU consequences and patients' quality of life might be better. Early detection of hyperlipidemia among CSU patients will pave a way for better interventions for this disease.

\section{Conflict of interest}

The authors declare that they have no conflict of interest.

\section{References}

1. Zuberbier T, Aberer W, Asero R, et al. The EAACI/GA (2) LEN/ EDF/WAO Guideline for the definition, classification, diagnosis, and management of urticaria: the 2013 revision and update. Allergy 2014; 69:868.

2. Zuberbier T., Aberer W., Asero R., Abdul Latiff A.H, Baker D., Ballmer-Weber B., et al. The EAACI/GA²LEN/EDF/WAO Guideline for the Definition, Classification, Diagnosis and Management of Urticaria. The 2017 Revision and Update; 61:316-320.

3. Kaplan AP, Greaves M. Pathogenesis of chronic urticaria. Clin Exp Allergy 2009; 39:777-787.

4. Vestergaard C, Deleuran M. Chronic spontaneous urticaria: latest developments in aetiology, diagnosis and therapy. Ther Adv Chronic Dis 2015; 6:304-13. doi: 10.1177/2040622315603951.

5. Staubach P, Eckhardt-Henn A, Dechene M, Vonend A, Metz M, Magerl M, et al. Quality of life in patients with chronic urticaria is 
differentially impaired and determined by psychiatric comorbidity. Br J Dermatol 2006; 154:294-298.

6. Vonakis BM, Vasagar K, Gibbons SP et al. Basophil Fc epsilon RI histamine release parallels expression of Src-homology 2- containing inositol phosphatases in chronic idiopathic urticaria. J Allergy Clin Immunol 2007; 119:441-448.

7. Tedeschi A, Asero R, Lorini M, Marzano AV, Cugno M. Plasma levels of matrix metalloproteinase-9 in chronic urticaria patients correlate with disease severity and C-reactive protein but not with circulating histamine-releasing factors. Clin Exp Allergy 2010; 40:875-881.

8. Lourenco FD, Azor MH, Santos JC, Prearo E, Maruta CW, Rivitti EA, et al. Activated status of basophils in chronic urticaria leads to interleukin-3 hyper-responsiveness and enhancement of histamine release induced by anti-IgE stimulus. Br J Dermatol 2008; 158:979-986.

9. Dos Santos JC, Azor MH, Nojima VY, Lourenco FD, Prearo E, Maruta CW, et al. Increased circulating pro-inflammatory cytokines and imbalanced regulatory $\mathrm{T}$-cell cytokines production in chronic idiopathic urticaria. Int Immunopharmacol 2008; 8:1433-1440.

10. Kasperska-Zajac A, Sztylc J, Machura E, Jop G. Plasma IL-6 concentration correlates with clinical disease activity and serum C-reactive protein concentration in chronic urticaria patients. Clin Exp Allergy 2011; 41:1386-1391.

11. Devaraj S, Rosenson RS, Jialal I. Metabolic syndrome: an appraisal of the pro-inflammatory and procoagulant status. Endocrinol Metab Clin North Am 2004; 33:431-453.

12. Kasperska-Zajac A. Acute-phase response in chronic urticaria. J Eur Acad Dermatol Venereol 2012; 26:665-672.

13. Ye YM, Jin HJ, Hwang EK, Nam YH, Kim JH, Shin YS, et al. Co-existence of chronic urticaria and metabolic syndrome: clinical implications. Acta Derm Venereol 2013; 93:156-160.

14. Berger A. Skin prick testing. BMJ 2002; 24,325(7361):414.

15. Konstantinou GN, Asero R, Ferrer M, Knol EF, Maurer M, Raap $\mathrm{U}$, et al. EAACI taskforce position paper: evidence for autoimmune urticaria and proposal for defining diagnostic criteria. Allergy 2013; 68(1):27-36.

16. Vonakis BM, Saini SS. New concepts in chronic urticaria. Curr Opin Immunol 2008; 20:709-716.

17. Chung SD, Tsai MC, Lin HC. Hyperlipidemia Is Associated with Chronic Urticaria: A Population-Based Study PLOS ONE. March 10, 2016.

18. Kobayashi S: About relationships between chronic urticaria and serum lipids (Abstract), The $76^{\text {th }}$ Annual Meeting of the Japanese Dermatological Association, 1977.

19. Kobayashi S, Gocho H, Yamamoto N. Serum lipids and constitutive fatty acids of all lipids in chronic urticaria, skin diseases and normal control (Abstract), The 84th Annual Meeting of Japanese Dermatological Association, 1985.

20. Kobayashi S. Investigation of the Roles of the Substances in Serum Lipids and Their Constitutive Fatty Acids in Chronic Urticaria. J Dermatol 1989; 16:196-206.

21. Siasos G, Tousoulis D, Oikonomou E, Zaromitidou M, Stefanadis C, Papavassiliou AG. Inflammatory markers in hyperlipidemia: from experimental models to clinical practice. Curr Pharm Des 2011; 17:4132-4146.

22. Mathelier-Fusade P. Drug-induced urticarias. Clin Rev Allergy Immunol 2006; 30:19-23.
23. Prevete N, Staiano RI, Granata F, Detoraki A, Necchi V, Ricci V, et al. Expression and function of Angiopoietins and their tie receptors in human basophils and mast cells. J Biol Regul Homeost Agents 2013; 27:827-839.

24. Woollard KJ. Immunological aspects of atherosclerosis. Clin Sci 2013; 125:221-235.

25. Lindstedt KA, Mayranpaa MI, Kovanen PT. Mast cells in vulnerable atherosclerotic plaques-a view to a kill. J Cell Mol Med 2007; 11:739-758.

26. Lee M, Calabresi L, Chiesa G, Franceschini G, Kovanen PT. Mast cell chymase degrades apoE and apoA-II in apoA-I-knockout mouse plasma and reduces its ability to promote cellular cholesterol efflux. Arterioscler Thromb Vasc Biol 2002; 22:1475-1481.

27. Sun J, Sukhova GK, Wolters PJ, Yang M, Kitamoto S, Libby P et al. Mast cells promote atherosclerosis by releasing proinflammatory cytokines. Nat Med 2007; 13:719-724.

28. Libby P, Sukhova G, Lee RT, Galis ZS. Cytokines regulate vascular functions related to stability of the atherosclerotic plaque. J Cardiovasc Pharmacol 1995; 25:S9-12.

29. Spinas E, Kritas SK, Saggini A, Mobili A, Caraffa A, Antinolfi P, et al. Role of mast cells in atherosclerosis: a classical inflammatory disease. Int J Immunopathol Pharmacol 2014; 27:517-521.

30. Kaplan A. Inflammation in chronic urticaria is not limited to the consequences of mast cell (or basophil) degranulation. Clin Exp Allergy 2010; 40:834-835.

31. Maurer M, Weller K, Bindslev-Jensen C, Gimenez-Arnau A, Bousquet PJ, Bousquet J, et al. Unmet clinical needs in chronic spontaneous urticaria. A GA (2) LEN task force report. Allergy 2011; 66:317-330.

32. Shachar I, Karin N. The dual roles of inflammatory cytokines and chemokines in the regulation of autoimmune diseases and their clinical implications. J Leukoc Biol 2013; 93:51-61.

33. Wilson LH, Eliason MJ, Leiferman KM, Hull CM, Powell DL. Treatment of refractory chronic urticaria with tumor necrosis factor-alfa inhibitors. J Am Acad Dermatol 2011; 64:1221-1222.

34. Wedi B, Novacovic V, Koerner M, Kapp A. Chronic urticaria serum induces histamine release, leukotriene production, and basophil CD63 surface expression---inhibitory effects of anti-inflammatory drugs. J Allergy Clin Immunol 2000; 105:552-560.

35. Ross, R. Atherosclerosis-an inflammatory disease. N Engl J Med 1999; 340:115-126.

36. Sherman, ML Spriggs DR, Arthur KA, Imamura K, Frei E., Kufe DW Recombinant human tumor necrosis factor administered as a five-day continuous infusion in cancer patients: phase I toxicity and effects on lipid metabolism. J Clin Oncol 1988; 6:344-350.

37. Feingold, K. Adi RS, Staprans I, Moser AH, Neese R, Verdier JA, Doerrler W, Grunfeld C. Diet affects the mechanisms by which TNF stimulates hepatic triglyceride production. Am J Physiol 1999; 259:E59-64.

38. Ryden, M, Dicker A, van Harmelen V, Hauner H, Brunnberg M, Perbeck L, Lonnqvist F, and Arner P. Mapping of early signaling events in tumor necrosis factor-alpha-mediated lipolysis in human fat cells. J Biol Chem 2002; 277:1085-1091.

39. Feingold, KR., Hardardottir I, Grunfeld C. Beneficial effects of cytokine induced hyperlipidemia. Z. Ernahrungswiss. 1998; 37(Suppl. 1):66-74.

40. De Fabiani, E., Mitro N., Anzulovich A.C, Pinelli A., Galli G., Crestani M. The negative effects of bile acids and tumor necrosis 
factor- $\alpha$ on the transcription of cholesterol $7 \alpha$-hydroxylase gene (CYP7A1) converge to hepatic nuclear factor-4. J Biol Chem 2001; 276:30708-30716.

41. Memon, RA, Moser AH, Shigenaga JK, Grunfeld C, Feingold KR. In vivo and in vitro regulation of sterol 27-hydroxylase in the liver during the acute phase response. Potential role of hepatocyte nuclear factor-1. J Biol Chem 2001; 276:30118-30126.

42. Piconi S, Trabattoni D, Iemoli E, Fusi ML, Villa ML, Milazzo F, et al. Immune profiles of patients with chronic idiopathic urticaria. Int Arch Allergy Immunol 2002; 128:59-66.

43. Pickup JC, Mattock MB, Chusney GD, Burt D. NIDDM as a disease of the innate immune system: association of acute-phase reactants and interleukin- 6 with metabolic syndrome X. Diabetologia 1997; 40:1286-1292.

44. Greenberg AS, Nordan RP, McIntosh J, Calvo JC, Scow RO, Jablons D. Interleukin-6 reduces lipoprotein lipase activity in adipose tissue of mice in vivo and in 3T3-L1 adipocytes: a possible role for interleukin-6 in cancer cachexia. Cancer Res 1992; 52:4113-4116.
45. Nonogaki K, Fuller GM, Fuentes NL, Moser AH, Staprans, Grunfeld C.1995. Interleukin-6 stimulates hepatic triglyceride secretion in rats. Endocrinology 1995; 136:2143-2149.

46. Stouthard JM, Romijn JA, Van der Poll T, Endert E, Klein S, Bakker PJ, et al. Endocrinologic and metabolic effects of interleukin-6 in humans. Am J Physiol 1995; 268:E813-9.

47. Pezeshkpoor F, Hosseini RF, Rafatpanah H, Shakerian B, Jabbari F, Zandkarimi MR, et al. Efficacy of Atorvastatin and Antihistamines in Comparison with Antihistamines plus Placebo in the Treatment of Chronic Idiopathic Urticaria: A Controlled Clinical Trial. Iran J Allergy Asthma Immunol 2012; 11(3):236-240.

48. Sheikh J. Autoantibodies to the high-affinity IgE receptor in chronic urticaria: how important are they? Curr Opin Allergy Clin Immunol 2005; 5:403-407.

49. Majlesi Y, Samorapoompichit P, Hauswirth AW, Schernthaner GH, Ghannadan M, Baghestanian M, et al. Dependent differentiation and $\mathrm{IgE}$-mediated histamine basophils and down modulate expression of the basophil-activation antigen CD203c/E-NPP3. J Leukoc Biol 2003; 73(1):107-117. 